\title{
Disruptive ethnography and knowledge co-creation
}

\author{
Peter Lugosi, PhD \\ Oxford School of Hospitality Management \\ Oxford Brookes University \\ United Kingdom \\ plugosi@brookes.ac.uk \\ ORCID ID: 0000-0002-7611-128X
}

Published as: Lugosi, P. (2018) Disruptive ethnography and knowledge co-creation. In Ren, C., Jóhannesson, G. and van der Duim, R. (Eds.) Co-creating Tourism Research: Towards Collaborative Ways of Knowing. Abingdon: Routledge, 55-72. ISBN: 978-1-138-22819-1.

(Please consult the final published version if citing)

\begin{abstract}
This chapter explores the role of disruptive practices within ethnographic research. Through fieldwork encounters, ethnographers inevitably influence the lives of the people being studied. Researchers have generally advocated reflexive approaches to examining relationships in the field and to the ways in which engagement shapes data. However, some have gone further, arguing for the merits of obtrusiveness as a strategy in fieldwork. Drawing on a multi-sited ethnographic study of hospitality venues, this chapter contributes to this area of debate by examining how obtrusive practices can generate insights regarding cognitive and socio-material processes in the production of consumption spaces. The chapter considers three areas of disruptive activity: firstly, embodied disruption, including co-presence, social interactions and engagement in actions that challenge the perceived social order; secondly, sonic disruption - changing music in a venue to provoke and observe consumer reactions; and finally, research-instigated visits with other consumers. The discussion examines how these practices were used to co-create knowledge regarding the production of space and the experience of consuming hospitality. The chapter considers critically the potential benefits alongside the ethical and methodological challenges of adopting such approaches.
\end{abstract}

\section{Introduction}

Advocates of 'objective', 'scientific' principles in research may seek to reduce the researcher's influence in data collection and analysis because it is seen to compromise rigour and validity (cf. Brotherton, 2015; Chang, 2014; Stoddart, 1986). Foregrounding what Hammersley (2011) has called 'methodology-as-technique', i.e. codified procedures and practices, offers ways to legitimise knowledge in academic valuation cultures based on normative logics of transparency and quality assurance (cf. Bell, Kothiyal, \& Willmott, 2017; Lugosi, 2009a; Woodside, 2010; 2017). However, critics have challenged the appropriateness of adopting this conception of knowledge generation within all forms of qualitative research (see e.g. Alvesson \& Sköldberg, 2009; Hammersley, 2011; Harrington, 2002; Lincoln \& Guba, 2013). The need to challenge claims of researcher objectivity is particularly 
important in ethnographic studies, which rely on extended personal engagement with the study context and the people participating in the research (Agar, 2008; Atkinson, Delamont, Coffey, Lofland, \& Lofland, 2007; Coffey, 1999). Interaction cannot be conceived as a passive set of activities: observing, listening and reflecting are active embodied and cognitive processes; data gathering also requires researchers to probe, to question and occasionally to challenge. Discussions of interactive methods such as interviews highlight that researchers often can and do utilise provocative elicitation techniques that encourage participants to reflect on their experiences and opinions (see e.g. Ravn \& Duff, 2015; Törrönen, 2002). Ethnographic enquiry introduces additional challenges to the notion of researcher neutrality. Ethnographers are rarely passive, inconspicuous observers in fieldwork; instead they interact with and are thus likely to influence the lives and socio-material ecologies they encounter through fieldwork (DeWalt \& DeWalt, 2011; Hammersley \& Atkinson, 2007; Law, 2004). Some ethnographers go further, placing disruption and the potential to initiate positive change as key drivers of their efforts (Craven \& Davis, 2013; Hale, 2008; Naples, 2003). The literature on ethnographic enquiry has thus shown that, regardless of its political and ideological ambitions, it is important to conceive such research endeavours as practices of knowledge or data co-creation rather than as attempts to capture objective realities (Beaulieu, 2010; Law, 2004; Musante, 2014).

Ethnographers have advocated adopting reflexive approaches to examining relationships in the field and to the ways in which interactions shape the data constructed through ethnography (see e.g. Coffey, 1999; Davies, 2008; Lichterman, 2017; Lumsden, 2009). Writers such as Harrington (2002) have gone further, debating the merits of obtrusiveness as a strategy in ethnographic fieldwork (see also Schwalbe, 2002). Harrington (2002) examined Schwalbe's (1996) ethnographic work on men's movements, which involved attending and participating in lengthy, complex group debates. During several of these interactions, Schwalbe voiced arguments that contradicted the views of others in the group. In doing so he compelled the other men to reflect on their thoughts and actions. Harrington (2002) argued that such obtrusiveness helped to reveal further nuances about the empirical case; it also added credibility to Schwalbe's conclusions by demonstrating his ability to adopt critical perspectives and to reflect on his positionality. Harrington's (2002) (and Schwalbe's) work thus suggests that it is important to examine further how obtrusiveness and disruption are entangled in ethnographic research.

This chapter advances these areas of debate by examining how explicitly and sometimes purposefully disruptive practices, involving social interactions, as well as spatial tactics, physical objects and acoustic technologies, can generate insights regarding cognitive and socio-material processes involved in the production of consumption of spaces. Disruptive practices can be defined as performative acts, involving human and non-human actors, that contradict and/or mis-perform expected, normalized and thus patterned ways of thinking, doing and feeling in social spaces. Disruptive practices can be seen to challenge the 'social order(s)' (Hunter, 1985) of community or communal spaces. However, this invocation of the notions of social order and contradictory practices is not built on an objectivist conception of space, group or even norms as things existing outside of performative practices. Rather, it is a performative understanding of space and culture, which are conceptualised as articulations of power, involving patterns of perceiving, interpreting, valuing and enacting through shared (co-produced) social, cultural and political reference points. 
The chapter draws on a multi-sited ethnographic study of hospitality (Lugosi, 2008, 2009b, 2014) and considers several disruptive fieldwork practices involving physical presence, clothing, music and the shaping of consumption patterns. The discussion examines how these practices were used to cocreate knowledge regarding the production of space and the experiences of consuming hospitality. The chapter considers critically the potential benefits alongside the ethical and methodological challenges of adopting such approaches.

\section{Co-creating spaces, experiences...and ethnographic knowledge}

Within this chapter, knowledge co-creation in ethnographic research is underpinned by certain conceptions of space and experiences of space. Space is not assumed to be a static set of relations between physical objects. Nevertheless, it is important to acknowledge the material aspects of spatial relations, which includes the physical properties of the environment, the layout, alongside luminosity, sounds, smells, ambient temperature and other qualities. The present discussion is built upon the view that humans (co)construct relationships, shared values and notions of identity as they interact with (and within) environments through various embodied and interpretative practices (cf. Bajde, 2013; Bettany, 2007; Canniford \& Bajde, 2016; Miller, 1995; Shove, Trentmann, \& Wilk, 2009).

Researchers have recognised that (consumption) experiences unfold over time through a sequence of activities, which have material, embodied and cognitive dimensions (Arnould, Price, \& Zinkhan, 2002; Carù \& Cova, 2003; Turner \& Bruner, 1986). Consumer experiences begin prior to service encounters, with anticipation, planning and preparation; they also continue beyond the physical encounter through various psychological, social and material practices, including reflection, recall, storytelling and post-event representation, for example via social media (cf. Moscardo, 2010; Quinlan Cutler \& Carmichael, 2010; Ryan, 2002; Sharpley, \& Stone, 2012; Wu \& Pearce, 2014). However, understanding the situational and performative nature of experiential consumption within socialmaterial consumer spaces continues to be a challenge for academic research (cf. Bærenholdt, Haldrup, Larsen, \& Urry, 2004; Cochoy, 2008; Fuentes, 2014; Giovanardi, Lucarelli, \& Decosta, 2014; Larsen, 2008; Lugosi, 2016).

Within tourism, hospitality, leisure and retail consumption settings, destination or venue operators may attempt to manipulate aspects of the environment and the nature of social interactions in order to shape perceptions, create stimulus responses and orchestrate behaviours (Berry, Wall, \& Carbone, 2006; Hemmington, 2007; Hoffman \& Turley, 2002; Lugosi, 2014). However, it is important to acknowledge consumers' roles in recognising, interpreting and responding to experiential 'clues' that are envisioned by their producers. Furthermore, it is also necessary to appreciate consumers' ability to manipulate the socio-material service encounter, resist attempts at organizational controls, and their potential to transform experiences as they enact them (cf. Carù \& Cova, 2006; Lugosi, 2008, 2009b; Edensor, 2001; van der Duim, 2007). Existing research thus suggests that it is necessary to conceptualise experiential consumption as complex, dynamic, multidimensional interactions between producers and consumers, or more generally between practices of production and consumption, within a performative process involving human and non-human factors.

Research into tourism and leisure consumption experiences frequently utilise post-experience recall methods, involving, for example, introspective reports, interviews and participant-generated imagery (e.g. Carù \& Cova, 2006; Garrod, 2008; Johns \& Clarke, 2001). Knowledge regarding 
consumption spaces and experiences is co-created between researcher and respondents through attempts by the researcher to orchestrate the nature of the data being generated. Researchers have also attempted to utilise so called 'naturally occurring' data, for example textual and visual material posted to social media, which may have been produced during or closely after the consumption experience (Osman, Johns, \& Lugosi, 2014; Watson, Morgan, \& Hemmington, 2008; Wu \& Pearce, 2014).

Self-report methods have been criticised for the potential biases caused by respondents' conscious attempts to edit their responses, for example to maintain status, alongside unconscious ones, including selective recall (cf. Barrett \& Barrett, 2001; Li, Scott, \& Walters, 2015). As an alternative, some researchers have developed mobile technologies to help capture aspects of the experience in-situ (see Birenboim, 2016; Quinlan Cutler, Carmichael, \& Doherty, 2014; Quinlan Cutler, Doherty, \& Carmichael, 2016); others have also sought to expand the scope and procedures of consumer experience research by incorporating psychophysiological methods to understand aspects of the social and physical environment that evoke particular reactions (Li, Scott, \& Walters, 2015). Such psychophysiological, technology-driven methods offer useful insights into stimulus responses within experiential consumption, which may be unconscious and captured in-situ; these methods are also driven by an underpinning assumption that they help to generate data 'scientifically' and 'objectively'. However, they reveal limited information about the complex nature of co-creation and sensemaking that is central to tourism, hospitality and leisure experiences.

Other researchers have continued to employ ethnography, autoethnography and various other forms of observational data-generation to examine the situational, performative nature of consumption experiences (see Andriotis, 2009; Cuthill, 2007a, 2007b; Lynch, 2005; Palmer, 2005; Weed, 2006). Methodological accounts from such studies suggest that, whilst some observation may be conducted with minimal disruption to consumers' on-site experiences, most involve some provocative interaction as researchers attempt to interrogate informants' thoughts, feelings and practices in context. However, in the remaining parts of this discussion I intend to explore the notion of disruptiveness further, arguing that engaging in explicitly (and occasionally purposefully) disruptive practices may be a useful strategy for generating data concerning spatial and experiential co-creation processes. In doing so, I seek to illustrate how knowledge regarding tourism, hospitality and leisure spaces and experiences of spaces is itself co-created.

\section{Disruptive practices and knowledge co-creation}

The empirical context for the current discussion of disruptive methods was a multi-sited ethnographic study of hospitality venues in the United Kingdom and Hungary. However, in the following pages I concentrate on my experiences in one fieldwork site - the 'Freelands' - a bar located in the south of England, which catered principally for gay and lesbian consumers. I worked at the Freelands for 27 months, while also visiting this and other venues as a patron throughout a 5-year period. In addition to the countless informal conversations I shared during this period, I conducted interviews with 26 informants, 19 of whom were interviewed repeatedly.

Two key challenges for the research were to understand the practices through which the bar was (re)produced as a particular type of hospitality (or hospitable) space, and how patrons interpreted their consumption experiences. In the remaining parts of this chapter I discuss three types of disruptive 
practice that I engaged in to help explore these issues: embodied performances of self; experiments with music; and researcher-instigated co-consumption.

\section{Embodied disruptions}

As other commentators on ethnography have posited, it is possible to argue that my physical presence in the fieldwork site was a disruptive act (cf. Lumsden, 2009; Stoddart, 1986). However, in this context my 'disruptive self' had a number of characteristics and manifestations. I was a heterosexual male, working and socialising in a venue frequented by gay and lesbian consumers; I was also a doctoral researcher (and an ethnographer), which was an unusual occupation in that setting. Throughout the period of my work, I regularly had to try to explain what I actually did as a student or academic. My sexuality was also a source of scrutiny and amusement for many of the patrons. Some of the regulars jokingly referred to me as a 'heti', a 'breeder' or even 'the man writing a book about us' when talking to me, or about me, and when introducing me to others. Being identified as a strange 'other' during some interactions was itself instructive as it served to illustrate how notions of insider and outsider were performed situationally. In some moments, sexuality was used to define the group or community and to ascribe my status or position; in other moments, my education or lifestyle choices, and thus my class-based identity was used to articulate group norms and to signify my social status in relation to them. However, it is important not to essentialise notions of gay/lesbian space or to simplistically propose that the consumers were a distinct, coherent and fixed community. The articulation and ascription of identities, boundaries or social statuses were performative acts. They should thus be viewed as being fluid and socially contextual rather than conveying a fixed set of values or social relations.

Importantly, our identities as they were performed at the bar could not be reduced to a singular dimension, i.e. sexuality or sexual orientation. Not everyone at the bar was comfortable with certain enacted and embodied forms of queer identification, particularly 'camp' performances of self. Binnie (1997), Dyer (2001) and Meyer (1994) argued that camp can be a political expression of sexual identification and thus an enactment of queer space. However, as Dyer (2001) observed, many gay men who are unable or unwilling to 'camp about', are excluded from gay culture. Some patrons felt comfortable talking with me precisely because I was not a (stereo)typical gay man (see Lugosi, 2006). In many cases I bonded with people through talking about other interests, for example music, drinks, food, TV programmes, travel, and other mundane aspects of life. Being different, and therefore disruptive, helped to enact, to perceive and thus to comprehend the diverse practices through which notions of (in)hospitable gay space were produced and experienced.

The disruptiveness of my embodied presence was further manifested in a number of unexpected but ethnographically interesting ways during social interactions. For example, on one night during the first few months of working there I was given a promotional t-shirt, which was several sizes too big for me. The loose clothing was swinging around and became distracting but rather than attempting to tuck the excess cloth into my trousers, I tied a knot in it. It subsequently became apparent how disruptive this seemingly insignificant act was. In tying the knot I had transgressed particular heteronormative practices of self-expression and incorporated a 'queer' form of body modification. Patrons and my 
colleagues behind the bar repeatedly pulled it, and commented on it, joking that it made me 'look gay' and speculating what it signified.

The 'display' and consumer surveillance of servers' bodies is associated with most commercial hospitality venues and interactive service work in tourism and leisure (cf. Erickson, 2004, 2009). In the Freelands, as in many other venues, the management exploited this by hiring certain types of people (i.e. young, male with athletic physiques). Questions of political correctness or discrimination never arose. Moreover, this culture of surveillance was not limited to just watching: people in the bar made us aware they were watching. Customers continuously told me to 'wear tighter trousers' and to 'tuck my shirt in.' The initial disruptive act of tying a knot in the t-shirt was the first of many, which helped me to appreciate the importance of embodied displays of sexuality, and the public scrutiny of the sexualised body as practices through which notions of gay space were (re)produced.

These observations raised an important set of issues concerning my position as a 'straight' researcher. Binnie (1997) for example warned against voyeurism and misrepresentation of gay people by heterosexual researchers. Reading the above passage may provoke accusations of giving a biased, reductive and homophobic account of 'hyper-sexualised' gay culture. Nevertheless, through such interactions, I certainly became conscious of how open, uncensored expressions of sexuality were ways in which gay space was performed. However, reactions to this and other audible and visible expressions of sexuality by different customers revealed both their awareness of practices and their ambivalence towards them. A number of lesbians and gay men disliked this type of behaviour. Crude references to sex were ways to construct certain masculine versions of gay space, which not everyone identified with.

One of the regular lesbian customers, Helen, said she only talked to one other man in the Freelands because 'gay men [had] nothing interesting to say. All they talked about is who they slept with and what they did with them in bed.' Similarly, Karen commented: 'if you sit and talk to two young gay men it is like talking to my nephew and niece. The standard of conversation is just piss-poor. It really is. It's like giggles and it's like: [she impersonates] "I fuckin went into the pub and I fuckin ad im."” Coupled with my observations and experiences, these perspectives helped to understand the discontinuous and contested notions of gay and lesbian space, which could be transformed as they were simultaneously produced and consumed.

\section{Sonic disruption and space}

The main music system in the Freelands was controlled from behind the bar and staff were encouraged to play certain genres of music. The music in the bar tended to be one of three main varieties: contemporary popular music (mostly vocal dance music); contemporary 'street soul' or modern 'Rhythm and Blues' (R\&B); harder club-oriented tracks (some purely instrumental but most with some synthesised vocals). The musical policy was utilitarian in offering consumable forms that the majority of people would appreciate. It is problematic to say that the bar played 'gay music' as any such notion represents an assemblage of artists, sounds and musical styles. 'Gay music' for many patrons was perhaps best embodied by bands such as Steps who produced uplifting, vocal, dance-oriented pop music. This was, however, an oversimplification. This kind of music represented a popularised and somewhat clichéd type of 'high-camp' gay identity. The key word here is 'popularised'. These types of bands were branded, often called 'manufactured' pop groups. They were formed as record producers 
put together a group of young, attractive men and women, who received contracts from large record companies. Producing highly consumable popular music, these bands received a great deal of publicity and marketing exposure. These were bands with a huge gay (read as gay male) following. They often played in venues such as G.A.Y., which was a popular Saturday night event that invested heavily in selfpromotion. Such artists and the genres of sounds they (re)produced were part of the acoustic lexicon of what the operators reproduced as gay culture in their spatial strategies.

Throughout my time in the Freelands I deliberately experimented with a range of music in order to ascertain people's reactions and attitudes towards music. Their reactions demonstrated the intimate relationship music had with the experiential proposition of the bar and its image. Moreover, people's commentary was indicative of their general tastes and the cultural practices they identified with. I tried diverse types of music including 80s rock, soul, funk, jazz or harder electronic tracks. These were often described as: 'not gay enough', 'too boring', 'too depressive', 'too hard', or 'too repetitive'. Deviations from the three main(stream) musical styles were often disapproved of, especially if these were noticeable or continuous. For example, it was acceptable to play 'Take on me' by A-ha-one the group's most famous and catchy songs from the 80 s. However, to play the entire album was excessive. People often frowned on harder rock, or R\&B and dance music that was not popular or recognisable. Playing this kind of music usually met with complaints from either the customers or the manager.

Again, it is important to avoid oversimplifying the relationship that music had with the hospitality propositions of the venue. It is also important to stress that this is not highlighted to construct a reductive view of the patrons as being a homogenous group. Quite the opposite: my attempts at sonic disruption helped to appreciate how music became another socio-material practice through which different groups sought to co-create ludic expressions of gay space. Disruptions in the patterning of music within the performance of space also served to highlight people's complex relationship with music. As with expressions of sexuality, different genres of music became talking points between certain patrons and me. The conversations that subsequently unfolded also helped to stress the divisiveness of musical performativity.

For example, as I previously discussed (see Lugosi, 2009b: 402-403), Danni, a man in his 20s who was part of an 'alternative rock' scene repeatedly stressed that he hated 'shit gay music'. Similar tensions were highlighted during other interviews:

Peter: What about music, what sort of music do they play in there?

Nicola: Cheesy pop.

Karen: They play the same music in every single pub I go to.

Peter: In every straight pub or gay pub?

Karen: Oh no not a straight pub. In a [straight] pub you'll listen to Oasis, Texas, a wide range...

Nicola: Good music.

Karen: You go into the Freelands, Whytes, Coast [other 'gay' venues], it's all "dud dud," I can't stand it. It's like, why can't they make one night of old music.

Nicola: Proper music, with actual instruments and singers.

Karen: It is not gay enough [for other people]. We are being stereotyped by the music.

Nicola: It's like 11-year-old music and gay music go hand in hand. 
(taken from Lugosi, 2009b: 403)

Music, it seems, was a contested practice used to ascribe qualities to the consumption space and the experiential propositions the operators (and some consumers) sought to co-create. On the one hand, it was deployed strategically to create affect and to communicate ludic values regarding the space, which were themselves entangled in broader marketing practices communicating that this was a space for a particular 'community' of consumption. On the other hand, these attempts to construct (and engage) particular conceptions of a community excluded many individuals who did not identify with such notions of queer identity.

\section{Researcher-instigated co-consumption}

A further and more problematic disruptive practice involved accompanying people to the Freelands, alongside other bars, sometimes without telling them anything about the venues in advance. All the males I accompanied to venues were heterosexual, except for one acquaintance (Guy). With the exception of one man (Carlos), when visiting 'gay venues' I always forewarned individuals who were uncomfortable with same-sex relationships, and they were always given the choice to decline. We discussed their experiences during and after visits.

These disruptive techniques enabled me to examine people's perceptions of the place, their attitudes, and their knowledge base in-situ. The emphasis was placed on the processes by which they recognised and assigned values to spaces, performances and materialities in particular situations. Discussing their experiences in turn also helped to understand their sense of social positioning and (dis)identification with certain aesthetic, cultural or moral values. In the following section I reflect on three visits in which I did not tell my fellow patrons about the venue, in each case briefly describing the individuals before providing a summary of my field notes written about the incidents. Following a discussion of the implications of these incidents, I go on to consider another instigated visit with three others who knew about the Freelands and its patrons.

\section{'Guy'}

Guy was a single 25-year-old gay man living in London. Guy had experience of London gay bars and clubs, although he did not frequent them. He often emphasised that he was not part of 'the scene':

Guy and I visited the Freelands on a Friday night; the bar was relatively quiet with about 20 customers (predominantly male and gay). The interesting point was that it took Guy nearly 45 minutes before he noticed he was among gay consumers and in a 'gay' bar. Despite the visual clues, and the overtly camp behaviour of some people, the clue that signalled this was a gay bar was a copy of $Q X$ [a 'gay listings and scene' magazine] on a neighbouring table.

\section{'Sonja'}

Sonja was a recently divorced woman, 30 years of age; she had little knowledge of gay culture and had no experience of gay venues: 
We went to the Freelands on a Saturday afternoon; it was relatively empty, with only three customers. During the two hours we spent there, more customers had arrived but the place was still fairly empty. Sonja did not realise it was a gay venue but noted that some of the men were staring at me and found this to be 'rude'.

\section{'Carlos'}

Carlos was a 30-year-old Portuguese male, married with one child. He lived in East London and did not frequent gay establishments. However, he did have vast experience of the hospitality industry, and as a result was well acquainted with a range of social types and cultural characteristics:

We went to the bar on a weekday afternoon. There were only two customers at the bar and the landlord who was also seated at the bar. Having got the drinks and sat down, Carlos did not ask, but announced that 'this was a gay bar.' When I asked how he came to that conclusion he pointed out that the 'three men were obviously gay.' It was interesting to note that we sat next to the large rainbow flag that decorated one of the walls although Carlos did not take any notice of this.

These disruptive ethnographic activities helped to identify two interrelated dimensions of how people interpreted socio-material practices in the co-creation of space. First was the 'involvement' dimension, which refers to the scope and intensity of social interactions and the extent to which people were aware of (socio-material) performative practices in specific situations. The second dimension concerned the socio-cultural knowledge, which stemmed from people's awareness of, and involvement in, wider social practices that provided them with knowledge and capacities with which to process situational information.

The first of the three cases brought to light the importance of situational awareness and involvement factors in consumption. Guy was familiar with gay culture, and its visual signifiers, but only reached the conclusion that he was in a gay space when he was presented with a specific (direct) signifier (the magazine). The behavioural patterns, and body language of the surrounding guests, were not noticeable enough for him to realise that he was among gay consumers. More specifically, his situational awareness and involvement was low. However, his wider knowledge of the London gay social scene, and of the magazine as a targeted niche publication, enabled him to deduce that this was a gay venue.

In the second example, Sonja was highly aware in the situation. At the same time, she was involved because she engaged with other people in the bar, although not verbally. However, she had no knowledge or experience of gay culture that could inform her assessment of the venue. She was aware of people watching, and being inquisitive, but interpreted this behaviour as simply being rude. She assumed that the place was unfriendly and that this could lead to conflict.

In the third example, Carlos concluded that this was a gay venue because of the behaviour and mannerisms of the two other patrons and the landlord. He was situationally aware and involved, which lead him to the conclusion that he was among gay people. Because he could identify more than one person as gay in that social context, he concluded that this was a gay bar. Additionally, he had sufficient knowledge of social practices to recognise a person's sexuality from their behaviour. However, he did 
not have the level of experience with gay culture, which would have equipped him with the knowledge that the flag had cultural significance. For Carlos the place-image was ambiguous and the venue was 'just a pub'. His categorisation of the place, as a 'gay pub', was because of the people in the venue and their expressive performances of self.

Beyond identifying underpinning factors that shaped people's perceptions in a venue, accompanying others to the Freelands also helped to appreciate the dynamic and co-performed nature of experiences in and of space. The following is an example of a visit with three heterosexual acquaintances who were fully aware of the bar and its patrons.

All the time when walking to the Freelands, Martin and Brian kept talking about going somewhere else and threatening that if anyone 'tried anything', they would start a fight. Jeanette kept reassuring them they would 'have a laugh.' We went in and walked straight to the bar. I could see they were all highly conscious of their surroundings. Martin and Brian both stood unnaturally upright, turning their heads constantly, scanning the room; Jeanette was already dancing around. We bought some drinks and I said hello to a few people. Brian saw that the garden was open and said he thought it was better if we sat outside. Martin agreed and Jeanette started laughing at them. [...] [We sat down at one of the tables in the garden.] James came out, greeted me with "hello straight boy", and kissed me on the cheek. I introduced him to the others. Brian looked visibly flustered and said to James "sorry, this is my first time in a place like this." James replied "I am usually hanging around bushes but I thought l'd come here for a change. That is what gay men do don't they?" Brian saw the joke and seemed to relax. [Later] When it came to the next round, Brian and Martin started arguing - both said the other one should go to the bar. Jeanette had been keen to go inside all the time and she gladly volunteered to get the drinks. [Later] They were closing up and we all went inside and sat at the back left corner on our own. Several people came over to say hello to us and both Martin and Brian got into conversations with people. [...] When Martin was talking to Ritchie about one of Jeanette's gay relatives, he used awkward terms such as 'he was someone like you' and 'that way inclined.' [...] Everyone seemed to find common topics of conversation and they seemed to relax. [All three of them talked to several different men during the evening.] [After leaving] Martin asked if anyone 'wanted a fag', and all three of them burst out laughing. [...] When we walked home, Martin and Brian constantly repeated the joke and made derogatory comments about being 'chatted up'.

During their time in the venue, the two men appeared to lower their boundaries and engage with the space and its patrons in constructive ways. The ability and willingness of the other patrons to perform the role of welcoming 'hosts' and the two men to be accepting 'guests' had the potential to transform the Freelands into a hospitable space. However, beyond the interactional setting, the two straight men immediately appeared to reject the ethical and social values co-created during the encounter through their continued enactment of homophobic practices. Disruptive ethnographic practice in this case sought to unsettle heteronormative assumptions, and as a result highlighted how these could be challenged, albeit temporarily, through the production and consumption of hospitality space. 
Ethnographers are increasingly engaging in mobile forms of participant observation, accompanying consumers during visits to tourism, hospitality and leisure sites (Cuthill, 2007a, 2007b; Thurnell-Read, 2012; Tutenges, 2015). The rationale is clear: these research strategies help to better understand how experiences are performed and co-constructed across time and space. However, the emphasis in methodological discussions of such mobile ethnographies continue to be on non-disruptive observation or on conforming participation even when researchers are actively engaged in the consumption experiences (cf. Thurnell-Read, 2011, 2012; Tutenges, 2015). The visits to the Freeland highlight how disruptiveness, and the purposeful exposure of consumers to unexpected social and material practices, can provide co-created insights regarding the production and consumption of space and consumers' experiences of those spaces. The important difference between following consumers across leisure landscapes and attempting to direct their destinations is that the latter scenario enables the researcher to explore anticipated factors that are specific to a particular research setting. The consumption venue operates as a quasi-experimental space in which certain variables such as the material and social practices are likely to be (re)enacted. The repeated presence of these practices can thus help to understand how different individuals perceive, interact with and potentially transform them in the experience co-creation process.

\section{Conclusion: The ethics and practicalities of disruptive ethnographies}

It is possible to argue that all ethnographic studies involve some disruptive practices. These can range from provoking reflection amongst informants to more radical interventions in the lives and spatial contexts being studied. Researchers may treat such disruptions in different ways, for example, denying their existence, trying to minimise them, mitigating their impacts or engaging critically and reflexively with the potential issues their disruptions raise. In this chapter I have examined how disruption and specific disruptive socio-material practices can be integrated in ethnographic fieldwork to co-create knowledge concerning the production and consumption of spaces and people's experiences of them. Some of these disruptions may not be intentional; nevertheless, whether created through accident or methodological intent, they help to question the processes through which experiential business propositions, cultures and identities are enacted.

The notion of disruption in general and the specific examples explored here raise a number of critical ethical and methodological questions. A key set of ethical concerns in my research relate to the absence of full consent and the potential to cause psychological harm to the people who are taken to venues embodying values that may clash with theirs, for research purposes without their knowledge. In my case I was always careful about who I brought to the bar: I did not wish to cause them distress, and I knew the individuals would be psychologically resilient enough that it would not cause any substantial harm. Nevertheless, in the current culture of bureaucratised ethical review and institutional disciplining, this would be considered highly problematic. At the very least, institutions would expect there to be a formal process of debriefing and the expectation of gaining post-'intervention' consent. These may be some of the ethical procedural strategies that researchers can adopt if attempting to utilise explicitly and occasionally purposefully disruptive elements in their fieldwork.

A more general critique of disruptiveness concerns the methodological flaws inherent in fieldwork practices that 'artificially' generate data. However, the underlying assumption in such critique is that there is naturally occurring data existing in some objective reality, which can be captured without any 
methodological influence. Whenever researchers engage in data collection, they inevitably become part of the social, spatial, material, representational and performative processes through which experiences are co-created, even if just by prompting respondents to recall them (Law, 2004; Law \& Urry, 2004). Perception, conception and therefore data generation is a collaborative effort between human and non-human agents; and any articulation of 'knowledge' or interpretation has the potential to be constantly made and remade through researcher and non-researcher-driven disruptions.

A broader and more radical approach to knowledge co-creation and disruptiveness may seek to position these performative, collaborative data-generation techniques at the centre of research strategies. Researchers are increasingly advocating the development of new forms of experimentalisms and 'experimental collaborations' (Estalella \& Sánchez-Criado, 2015), for example in creating new technologies and organisational arrangements (cf. Carrozza \& Gaspar, 2016; Corsín Jiménez, 2014; Marcus, 2014). Knowledge creation in such projects is underpinned by a desire to disrupt existing practices through involving multiple stakeholders for whom interventions matter. Disruption, however, is part of a productive process insofar as it helps to create new understandings, behaviours or technologies. More specifically, what may be called constructive or productive disruption comes to describe the goal of research and the underpinning methodological techniques used to achieve it. Importantly, in the current socio-political drive towards demonstrating the wider impacts of (academic) enquiry, foregrounding the potential of constructive or productive disruption to drive impactful knowledge co-creation may help to legitimise some research (see e.g. Lugosi, 2017).

In contrast, researchers may try to minimise their disruptive acts in data collection, or utilise alternative strategies involving data or researcher triangulation to help to generate a richer and arguably more credible set of data in an attempt to compensate for researcher-instigated disruptions. The deployment of triangulation techniques may be driven by an instrumental goal of legitimising the knowledge generation process in valuation cultures based on 'proceduralism' (Hammersley, 2011). However, triangulation may be underpinned by a more philosophical desire to construct alternative readings and perspectives on social phenomena, which is not based on objectivist assumptions. Researchers may also engage in critical reflexivity before, during and after data collection to better understand the impacts that their disruptive practices may have (had) on their respondents and their data.

In conclusion, the different examples of disruptiveness considered here may not be possible or desirable in other studies; and I am not seeking to advocate unethical behaviour. Nevertheless, this chapter has sought to: firstly, stress the potential value of disruptive practices in generating nuanced context-specific ethnographic insights; and secondly, prompt further dialogue and thinking about how the principle of disruptive practices can be developed into usable methods in future studies. At the very least, I hope that this discussion will encourage researchers in general and ethnographers specifically to critically reflect upon the disruptive socio-material practices that may emerge accidentally or purposefully in their attempts to co-create knowledge.

\section{References}

Agar, M. H. (2008). The professional stranger: An informal introduction to ethnography (2nd ed.). Bingley: Emerald. 
Alvesson, M., \& Sköldberg, K. (2009). Reflexive methodology: New vistas for qualitative research (2nd ed.). London: Sage.

Andriotis, K. (2009). Sacred site experience: A phenomenological study. Annals of Tourism Research, 36(1), 64-84, DOI: 10.1016/j.annals.2008.10.003.

Arnould, E., Price, L., \& Zinkhan, G. (2002). Consumers. New York: McGraw-Hill.

Atkinson, P., Delamont, S., Coffey, A., Lofland, J., \& Lofland, L. (Eds.). (2007). Handbook of Ethnography. London: Sage.

Bajde, D. (2013). Consumer culture theory (re) visits actor-network theory: Flattening consumption studies. Marketing Theory, 13(2), 227-242, DOI: 10.1177/1470593113477887.

Barrett, L. F., \& Barrett, D. J. (2001). An introduction to computerized experience sampling in psychology. Social Science Computer Review, 19(2), 175-185, DOI: 10.1177/89443930101900204.

Beaulieu, A. (2010). From co-location to co-presence: Shifts in the use of ethnography for the study of knowledge. Social Studies of Science, 40(3), 453-470. DOI: 10.1177/0306312709359219.

Bell, E., Kothiyal, N., \& Willmott, H. (2017). Methodology-as-Technique and the meaning of rigour in globalized management research. British Journal of Management, 28(3), 534-550. DOI: 10.1111/1467-8551.12205.

Berry, L.L., Wall, E.A., \& Carbone, L.P. (2006). Service clues and customer assessment of the service experience: Lessons from marketing. Academy of Management Perspectives, 20(2), 43-57, DOI: 10.5465/AMP.2006.20591004.

Bettany, S. (2007). The material-semiotics of consumption, or, where (and what) are the objects in consumer culture theory? In R.W. Belk \& J.F. Sherry (Eds.), Consumer Culture Theory (Research in Consumer Behavior, Vol. 11) (pp. 41-56). Oxford, UK: JAI Press.

Bærenholdt, J. O., Haldrup, M., Larsen, J., \& Urry, J. (2004). Performing tourist places. Aldershot: Ashgate.

Binnie, J. (1997). Coming out of geography: Towards a queer epistemology? Environment and Planning D: Society and Space, 15(2), 223-237. DOI: 10.1068/d150223.

Birenboim, A. (2016). New approaches to the study of tourist experiences in time and space. Tourism Geographies, 18(1), 9-17, DOI: 10.1080/14616688.2015.1122078.

Brotherton, B. (2015). Researching hospitality and tourism (2nd ed.). London: Sage.

Canniford, R., \& Bajde, D. (2016). Assembling consumption: Researching actors, networks and markets. Abingdon: Routledge.

Carù, A., \& Cova, B. (2003). Revisiting consumption experience a more humble but complete view of the concept. Marketing theory, 3(2), 267-286, DOI: 10.1177/14705931030032004.

Carù, A., \& Cova, B. (2006). How to facilitate immersion in a consumption experience: Appropriation operations and service elements. Journal of Consumer Behaviour, 5(1), 4-14, DOI: 10.1002/cb.30.

Carrozza, C., \& Gaspar, A. (2016). Performing digital ways of knowing: Epistemic walks with methodsas-prototypes. Graduate Journal of Social Science, 12(2), 58-76.

Chang, M. (2014). Principles of scientific methods. Broken Sound Parkway: CRC Press.

Cochoy, F. (2008). Calculation, qualculation, calqulation: shopping cart arithmetic, equipped cognition and the clustered consumer. Marketing Theory, 8(1), 15-44, DOI: 10.1177/1470593107086483.

Coffey, A. (1999). The ethnographic self: Fieldwork and the representation of identity. London: Sage. 
Corsín Jiménez, A. (2014). Introduction: The prototype: more than many and less than one. Journal of Cultural Economy, 7(4), 381-398, DOI: 10.1080/17530350.2013.858059.

Craven, C., \& Davis, D. A. (2013). Feminist activist ethnography: Counterpoints to neoliberalism in North America. Lanham, MD: Lexington Books.

Cuthill, V. (2007a). Sensing and performing hospitalities and socialities of tourist places: Eating and drinking out in Harrogate and Whitehaven. In J. Germann Molz, \& S. Gibson (Eds.), Mobilizing hospitality (pp. 83-100). Aldershot: Ashgate.

Cuthill, V. (2007b). Consuming Harrogate: Performing Betty's café and Revolution vodka bar. Space and Culture, 10(1), 64-76, DOI: 10.1177/1206331206296137.

Davies, C. A. (2008). Reflexive ethnography: A guide to researching selves and others (2nd ed.). London: Routledge.

DeWalt, K. M., \& DeWalt, B. R. (2011). Participant observation: A guide for fieldworkers (2nd ed.). Lanham, MD: Altamira.

Dyer, R. (2001). The culture of queers. London: Routledge

Edensor, T. (2001). Performing tourism, staging tourism: (Re) producing tourist space and practice. Tourist studies, 1(1), 59-81, DOI: 10.1177/146879760100100104.

Erickson, K. (2004). Bodies at work: Performing service in American restaurants. Space and Culture, 7(1), 76-89, DOI: 10.1177/1206331203256581.

Erickson, K. A. (2009). The Hungry Cowboy: Service and community in a neighborhood restaurant. Jackson, MS: University Press of Mississippi.

Estalella, A., \& Sánchez-Criado, T. (2015). Experimental collaborations: An invocation for the redistribution of social research. Convergence: The International Journal of Research into New Media Technologies, 21(3), 301-305, DOI: 10.1177/1354856515579839.

Fuentes, C. (2014). Green materialities: Marketing and the socio-material construction of green products. Business Strategy and the Environment, 23(2), 105-116, DOI: 10.1002/bse.1768.

Garrod, B. (2008). Exploring place perception a photo-based analysis. Annals of Tourism Research, 35(2), 381-401, DOI: 10.1016/j.annals.2007.09.004.

Giovanardi, M., Lucarelli, A., \& Decosta, P. L. E. (2014). Co-performing tourism places: The "Pink Night" festival. Annals of Tourism Research, 44, 102-115, DOI: 10.1016/j.annals.2013.09.004.

Hale, C. R. (Ed.). (2008). Engaging contradictions: Theory, politics, and methods of activist scholarship. Berkeley, CA: University of California Press.

Hammersley, M. (2011). Methodology: Who needs it? London: Sage.

Hammersley, M., \& Atkinson, P. (2007). Ethnography: Principles in practice (3rd ed.). Abingdon: Routledge.

Harrington, B. (2002). Obtrusiveness as strategy in ethnographic research. Qualitative Sociology, 25(1), 49-61, DOI: 10.1023/A:1014352107176.

Hemmington, N. (2007). From service to experience: Understanding and defining the hospitality business. The Service Industries Journal, 27(6), 747-755, DOI: 10.1080/02642060701453221.

Hoffman, K., \& Turley, L. (2002). Atmospherics, service encounters and consumer decision making: An integrative perspective. Journal of Marketing Theory and Practice, 10(3), 33-47, DOI: 10.1080/10696679.2002.11501918. 
Hunter, A. (1985). Private, parochial and public social orders: The problem of crime and incivility in urban communities. In G. D. Suttles, \& M. N. Zald (Eds.), The challenges of social control: Citizenship and institution building in modern society (pp. 230-242). Norwood, NJ: Ablex.

Johns, N., \& Clarke, V. (2001). Mythological analysis of boating tourism. Annals of Tourism Research, 28(2), 334-359, DOI: 10.1016/S0160-7383(00)00063-3.

Larsen, J. (2008). Practices and flows of digital photography: An ethnographic framework. Mobilities, 3(1), 141-160, DOI: 10.1080/17450100701797398.

Law, J. (2004). After method: Mess in social science research. Abingdon: Routledge.

Law, J., \& Urry, J. (2004). Enacting the social. Economy and Society, 33(3), 390-410, DOI: 10.1080/0308514042000225716.

Li, S., Scott, N., \& Walters, G. (2015). Current and potential methods for measuring emotion in tourism experiences: A review. Current Issues in Tourism, 18(9), 805-827, DOI: 10.1080/13683500.2014.975679.

Lichterman, P. (2017). Interpretive reflexivity in ethnography. Ethnography, 18(1), 35-45, DOI: $10.1177 / 1466138115592418$.

Lincoln, Y. S., \& Guba, E. G. (2013). The Constructivist Credo. Walnut Creek, CA: Left Coast Press.

Lugosi, P. (2006). Between overt and covert research: Concealment and disclosure in and ethnographic study of commercial hospitality. Qualitative Inquiry, 12(3), 541-561, DOI: $10.1177 / 1077800405282801$.

Lugosi, P. (2008). Hospitality spaces, hospitable moments: Consumer encounters and affective experiences in commercial settings. Journal of Foodservice, 19(2), 139-149, DOI: 10.1111/j.17454506.2008.00092.x.

Lugosi, P. (2009a). Ethnography, ethnographers and hospitality research: Communities, tensions and affiliations. Tourism and Hospitality Planning and Development, 6(2), 95-107, DOI: $10.1080 / 14790530902981431$.

Lugosi, P. (2009b). The production of hospitable space: Commercial propositions and consumer cocreation in a bar operation. Space and Culture, 12(4), 396-411, DOI: 10.1177/1206331209348083.

Lugosi, P. (2014). Mobilising identity and culture in experience co-creation and venue operation. Tourism Management, 40, 165-179, DOI: 10.1016/j.tourman.2013.06.005.

Lugosi, P. (2016). Socio-technological authentication. Annals of Tourism Research, 58, 100-113, DOI: 10.1016/j.annals.2016.02.015.

Lugosi, P. (2017). Using abstract concepts in impact-focussed organisational research: An empirical example deploying 'hospitality'. Qualitative Research in Organizations and Management, 12(1), 18-34, DOI: 10.1108/QROM-02-2016-1363.

Lumsden, K. (2009). “Don't ask a women to do another women's job': Gendered interactions and the emotional ethnographer', Sociology, 43(3) 497-513, DOI: 10.1177/0038038509103205.

Lynch, P. A. (2005). Sociological impressionism in a hospitality context. Annals of Tourism Research, 32(3), 527-548, DOI: 10.1016/j.annals.2004.09.005.

Marcus, G. (2014). Prototyping and contemporary anthropological experiments with ethnographic method. Journal of Cultural Economy, 7(4), 399-410, DOI: 10.1080/17530350.2013.858061.

Meyer, M. (Ed.) (1994). The politics and poetics of camp. London: Routledge

Miller, D. (Eds.). (2005). Acknowledging consumption. London: Routledge. 
Moscardo, G. (2010). The shaping of tourist experience: the importance of stories and themes. In: M. Morgan, P. Lugosi, \& J. R. B. Ritchie (Eds.), The tourism and leisure experience: Consumer and managerial perspectives (pp. 43-58). Bristol: Channel View.

Musante, K. (2014). Participant observation. In H. R. Bernard \& C. C. Gravlee (Eds.), Handbook of methods in cultural anthropology (pp. 251-292). Lanham, MD: Rowman \& Littlefield.

Naples, N. A. (2003). Feminism and method: Ethnography, discourse analysis, and activist research. New York, NY: Routledge.

Osman, H., Johns, N., \& Lugosi, P. (2014). Commercial hospitality in destination experiences: McDonald's and tourists' consumption of space. Tourism Management, 42, 238-247, DOI: 10.1016/j.tourman.2013.12.009.

Palmer, C. (2005). An ethnography of Englishness: Experiencing identity through tourism. Annals of Tourism Research, 32(1), 7-27, DOI: 10.1016/j.annals.2004.04.006.

Paterson, M. (2006). Consumption and everyday life. Abingdon: Routledge.

Quinlan Cutler, S., \& Carmichael, B. A. (2010). The dimensions of the tourist experience. In: M. Morgan, P. Lugosi, \& J. R. B. Ritchie (Eds.), The tourism and leisure experience: Consumer and managerial perspectives (pp. 3-26). Bristol: Channel View.

Quinlan Cutler, S., Carmichael, B., \& Doherty, S. (2014). The Inca Trail experience: Does the journey matter? Annals of Tourism Research, 45, 152-166, DOI: 10.1016/j.annals.2013.12.016.

Quinlan Cutler, S., Doherty, S., \& Carmichael, B. (2016). The experience sampling method: Examining its use and potential in tourist experience research. Current Issues in Tourism, 1-23, DOI: 10.1080/13683500.2015.1131670.

Ravn, S., \& Duff, C. (2015). Putting the party down on paper: A novel method for mapping youth drug use in private settings. Health \& Place, 31, 124-132, DOI: 10.1016/j.healthplace.2014.11.010.

Ryan, C. (Ed.). (2002). The tourist experience (2nd ed.). New York: Continuum.

Schwalbe, M. (1996). Unlocking the iron cage: The men's movement, gender politics, and American culture. New York: Oxford University Press.

Schwalbe, M. (2002). Everything is data: A response to Brooke Harrington. Qualitative Sociology, 25(1), 63-65, DOI: 10.1023/A:1014304224014.

Sharpley, R., \& Stone, P. (Eds.) (2012). Contemporary tourist experience: Concepts and consequences. Abingdon: Routledge.

Shove, E., Trentmann, F., \& Wilk, R. (Eds.). (2009). Time, consumption and everyday life: Practice, materiality and culture. Oxford: Berg.

Stoddart, K. (1986). The presentation of everyday life: Some textual strategies for "adequate ethnography". Urban Life, 15(1), 103-121, DOI: 10.1177/0098303986015001004.

Thurnell-Read, T. (2011). 'Common-sense' research: Senses, emotions and embodiment in researching stag tourism in Eastern Europe. Methodological Innovations Online, 6(3), 39-49, DOI: 10.4256/mio.2011.005.

Thurnell-Read, T. (2012). Tourism place and space: British stag tourism in Poland. Annals of Tourism Research, 39(2), 801-819, DOI: 10.1016/j.annals.2011.09.009.

Törrönen, J. (2002). Semiotic theory on qualitative interviewing using stimulus texts. Qualitative Research, 2(3), 343-362, DOI: 10.1177/146879410200200304. 
Turner, V. W., \& Bruner, E. M. (Eds.). (1986). The anthropology of experience. Urbana, IL: University of Illinois Press.

Tutenges, S. (2015). Pub crawls at a Bulgarian nightlife resort: A case study using crowd theory. Tourist Studies, 15(3), 283-299, DOI: 10.1177/1468797615597856.

van der Duim, R. (2007). Tourismscapes: An actor-network perspective. Annals of Tourism Research, 34(4), 961-976, DOI: 10.1016/j.annals.2007.05.008.

Watson, P., Morgan, M., \& Hemmington, N. (2008). Online communities and the sharing of extraordinary restaurant experiences. Journal of Foodservice, 19(6), 289-302, DOI: 10.1111/j.1748-0159.2008.00110.x.

Weed, M. (2006). The story of an ethnography: The experience of watching the 2002 World Cup in the pub. Soccer and Society, 7(1), 76-95., DOI: 10.1080/14660970500355603

Woodside, A. G. (2010). Bridging the chasm between survey and case study research: Research methods for achieving generalization, accuracy, and complexity. Industrial Marketing Management, 39(1), 64-75, DOI: 10.1016/j.indmarman.2009.03.017.

Woodside, A. G. (2017). Case study research: Core skills using 15 genres. Bingley: Emerald Group Publishing.

Wu, M. Y., \& Pearce, P. L. (2014). Chinese recreational vehicle users in Australia: A netnographic study of tourist motivation. Tourism Management, 43, 22-35, DOI: 10.1016/j.tourman.2014.01.010. 